\title{
Peran Keputusan Pembelian Dalam Memediasi Persepsi Risiko Terhadap Niat Beli Online Pada Online Shop SHOPEE
}

\author{
Dheasey Amboningtyas \\ Universitas Pandanaran \\ dheasey@unpand.ac.id \\ Leonardo Budi Hasiholan \\ Universitas Pandanaran \\ leonardobudihas@yahoo.co.id \\ Yunni Rusmawati DJ \\ Universitas Islam Lamongan \\ yunnirusmawati@unisla.ac.id
}

\begin{abstract}
Abstrak Di era ini, transaksi online dianggap menjadi lebih praktis dan dapat mengefisienkan waktu namun, bertransaksi online tidak terlepas dari ketidakpastian keputusan pembeliaan yang dirasakan konsumen dan dianggap sebagai persepsi risiko yang akan dapat mempengaruhi kepercayaan serta niat beli konsumen untuk bertransaksi online. Oleh karena itu, penelitian ini bertujuan untuk mengetahui peran keputusan pembeliaan dalam memediasi persepsi risiko terhadap niat beli online pada online shop Shopee untuk konsumen di Kota Semarang. Populasi dalam penelitian ini adalah 100 orang warga Kota Semarang yang sudah ditentukan kriterianya. Pemilihan sampel dilakukan dengan metode Purposive Sampling dan Sample Fraction. Hasil dari penelitian ini menunjukkan bahwa persepsi risiko berpengaruh negatif signifikan terhadap keputusan pembeliaan. Persepsi risiko juga mempunyai pengaruh negatif signifikan terhadap niat beli online pada online shop Shopee. Keputusan pembeliaan berpengaruh positif signifikan terhadap niat beli online pada online shop Shopee dan keputusan pembeliaan secara signifikan mampu memediasi hubungan antara persepsi risiko terhadap niat beli online pada online shop Shopee. Saran untuk online shop Shopee perlu untuk meminimalisir risiko yang terjadi saat berbelanja online serta diharapkan Shopee harus dapat mempertahankan dan meningkatkan kepercayaan konsumen dalam bertransaksi online
\end{abstract}

Kata Kunci Keputusan pembeliian, Persepsi risiko, dan Niat beli online 


\section{PENDAHULUAN}

Seiring dengan berkembangnya zaman, teknologi semakin maju. Contoh dari majunya teknologi yaitu intenet yang saat ini sudah menjadi kebutuhan pokok atau primer setiap orang, dari anak kecil hingga orang tua. Era globalisasi saat ini menjadikan perkembangan teknologi informasi yang berkembang semakin pesat. Perkembangan teknologi tersebut membawa perubahan di dalam gaya hidup masyarakat modern saat ini yang menjadi lebih praktis. Kehadiran internet saat ini dapat memberikan kemudahan di dalam berkomunikasi dan bertukar informasi yang dapat diakses oleh seluruh orang di dunia. Kemudahan memanfaatkan internet memberikan dampak pada berbagai aspek kehidupan manusia, salah satunya gaya hidup manusia yang menjadi semakin praktis (Sujana dan Suprapti, 2015). Internet saat ini seperti telah menjadi kebutuhan pokok yang sangat penting di dalam setiap aktivitas yang dilakukan oleh manusia. Di Indonesia pertumbuhan internet telah mengalami peningkatan (antaranews.com).

Dengan adanya internet semuanya menjadi mudah, termasuk dalam hal belanja kebutuhan sehari hari, entah dari kebutuhan primer hingga kebutuhan tersier setiap orang. Online shopping sudah menjadi aktivitas sehari - hari, hampir setiap hari orang tak pernah lupa untuk berkunjung ke aplikasi online shopping di smartphone mereka. Dari survey yang dilakukan iprice.co.id tiga aplikasi online shopping yang paling begengsi di Indonesia adalah SHOPEE sebagai peringkat pertama aplikasi online shop yang diminati. Aplikasi peringkat dua setelah SHOPEE adalah TOKOPEDIA, lalu peringkat tiga adalah LAZADA. Berbelanja melalui internet sudah menjadi pilihan pertama bagi konsumen untuk melakukan transaksi jual beli, selain menghemat waktu, biaya dan tenaga, belanja melalui internet dapat memudahkan kita untuk melihat banyak pilihan barang dari semua toko yang ada di aplikasi E-Commerce. Menurut Sonja dan Erwald (2003) dalam Sukawati (2018) menjelaskan bahwa berbelanja online memiliki keunikan sendiri karena konsumen dihadapkan dengan ketidakpastian, anonim, minimnya kontrol dan potensi dalam pengambilan kesempatan karena konsumen tidak bisa mengkontrol secara pasti pemenuhan kebutuhannya ketika ia membeli produk yang disebabkan oleh tidak bisanya konsumen untuk melihat produk yang akan dibeli secara langsung

Dalam melakukan belanja online, ada beberapa faktor yang mempengaruhi keputusan pembelian secara online. Faktor pertama yaitu harga. Seringkali harga dijadikan sebagai nilai yang dihubungkan dengan manfaat yang dirasa atas suatu barang atau jasa (Adiningsih (2018). Umumnya konsumen akan membandingkan harga dari beberapa produsen dan mencari harga yang paling sesuai dengan kualitas barang yang dibutuhkan. Selain itu konsumen akan lebih berhati - hati untuk mempertimbangkan masalah produk, mengingat produk yang mereka akan beli tidak berwujud secara nyata shingga tidak ada jaminan bahwa biaya yang mereka keluarkan untuk transaksi produk akan sesuai dengan produk yang mereka harapkan. Semua data itu dapat dilihat pada poin cheaper produt prices pada data polling Online shop popularity. Dari hasil tersebut terbukti bahwa SHOPEE dengan prosentase 18,00\% jauh mengungguli ECommerce LAZADA dengan prosentase $13,50 \%$ dan TOKOPEDIA dengan prosentase $13,30 \%$

Faktor selanjutnya yang tak kalah penting adalah persepsi resiko. Dimana persepsi terhadap resiko adalah persepsi negatif konsumen atas sejumlah aktifitas yang 
didasarkan pada hasil yang negatif dan memungkinkan bahwa hasil tersebut menjadi nyata (Ferrinadewi, 2008). pada Online Shop popularity poin authentic product yang dapat menjadi kegalauan konsumen dalam keaslian produk dimana SHOPEE dengan prosentase 4,2\% kembali tertinggal dari TOKOPEDIA dengan 4,3\% dan LAZADA yang jauh mengungguli dengan prosentase $7,2 \%$. Kemudia poin easy return policy pada tabel Online shop popularity dimana konsumen dapat mengajukan pengembalian dana ketika barang tidak tersedia dan pengembalian barang ketika barang tidak sesuai dengan pesanan, SHOPEE dengan prosentase 4,5\% masih tertinggal dari LAZADA dengan prosentase 5,4\% dan TOKOPEDIA dengan prosentase 5,3\%.

Perumusan masalah pada penelitian ini adalah

1. Bagaimana dan sejauh mana peranan keputusan pembeliaan terhadap kepercayaan niat beli online pada aplikasi online shop SHOPEE?

2. Bagaimana dan sejauh mana persepsi akan resiko berpengaruh terhadap niat beli online pada aplikasi online shop SHOPEE ?

3. Bagaimana dan sejauh mana keputusan pembelian dapat mengintervensi pengaruh harga, dan persepsi akan resiko terhadap kepercayaan konsumen?

\section{LANDASAN TEORI}

Pemasaran adalah mengidentifikasi dan memenuhi kebutuhan manusia dan sosial. Salah satu definisi yang baik dan singkat dari pemasaran adalah memenuhi kebutuhan dengan cara yang menguntungkan (Kotler \& Keller 2012:5).

Pada dasarnya ruang lingkup pemasaran dapat dilihat dari empat kebijakan pemasaran yang biasa disebut bauran pemasaran (marketing mix). Komponen marketing mix tersebut adalah:

a. Product (Produk)

Produk adalah sesuatu yang kita buat untuk memenuhi kebutuhan para konsumen dari permintaan pasar.

b. Price (Harga)

Harga adalah jumlah uang yang harus dikeluarkan untuk mendapatkan barang atau jasa yang diinginkan besert

a dengan pelayanannya.

c. Place (Distribusi/Tempat)

Pemasaran menggunakan saluran distribusi untuk memasarkan barang dan jasanya. Tempat adalah suatu lahan untuk mendistribusikan barang dan jasa sesuai kebutuhan konsumen.

d. Promotion (Promosi)

Promosi adalah semua kegiatan perusahaan untuk memperkenalkan produk dan bertujuan agar konsumen tertarik untuk membelinya. Dalam promosi terdapat kombinasi strategis yang paling baik yang dikenal bauran promosi (Promotion Mix) yang terdiri dari empat komponen utama yaitu periklanan (advertizing), promosi penjualan (sales promotion), pubilisitas (publicity), dan penjualan pribadi (personal selling). 


\section{Persepsi Akan Resiko}

Persepsi resiko adalah ukuran sebelumnya manfaat yang dirasakan dan kemudahan penggunaan yang dirasakan sebelum membeli produk atau jasa, berdasarkan tujuan beli konsumen. Pride dan Ferrel dalam Sangadji dan Sopiah (2013) menyatakan persepsi resiko merupakan bagian dari faktor psikologis yang mempengaruhi keputusan pembelian. Dua alasan penting mengapa pelanggan tidak membeli produk atau jasa di internet adalah masalah keamanan belanja online dan privasi informasi pribadi.Penelitiaan A. Haekal (2015) menyatakan tingkat resiko dalam berbelanja secara online tergantung pada persepsi konsumen dalam memperkirakan tinggi rendahnya resiko yang akan dialami ketika menggunakan internet untuk berbelanja. Persepsi resiko secara keseluruhan terdiri dari beberapa dimensi, yaitu: Reiko Sosial, Resiko Waktu, Resiko Finansial, Resiko Fisik, Resiko Fisik Fungsional, Resiko Psikologis.

\section{Keputusan Pembelian}

Keputusan pembelian yang dilakukan oleh konsumen dapat terjadi apabila kosumen sudah mendapatkan pelayanan dari pemberian jasa dan setelah itu konsumen merasakan adanya kepuasan dan ketidakpuasan, maka dari itu konsep- konsep keputusan pembelian tidak lepas dari konsep kepuasan pelanggan. Secara umum manusia bertindak rasional dan mempertimbangkan segala jenis informasi yang tersedia dan mempertimbangkan segala sesuatu yang mungkin bisa muncul dari tindakannya sebelum melakukan sebuah perilaku tertentu.

\section{Niat Beli Online}

Niat membeli berkaitan erat dengan keputusan pembelian konsumen, niat digunakan untuk memprediksi kecenderungan seseorang akan melakukan atau tidak melakukan perilaku membeli. Niat merupakan kecenderungan atau keinginan yang kuat pada individu untuk melakukan perilaku tertentu. Niat merupakan indikasi dari seberapa kuat keinginan individu untuk mewujudkan suatu perilaku, dengan kata lain semakin kuat keinginan individu tersebut semakin besar kemungkinan suatu perilaku diwujudkan, hal ini dikemukakan oleh (Sumarwan, 2011).

\section{METODOLOGI PENELITIAN}

Jenis penelitian yang digunakan dalam penelitian ini yaitu penelitian kuantitatif. Menurut Sugiyono (2015) Metode kuantitatif merupakan suatu metode penelitian yang bersifat induktif, objektif dan ilmiyah dimana data yang diperoleh berupa angka-angka (score, nilai) atau pertanyaan-pertanyaan yang dinilai, dan dianalisis dengan analisis statistik.

Sugiyono (2010) menjelaskan sebagai berikut :

"Populasi adalah wilayah generasi yang terdiri atas obyek/subyek yang mmpunyai kualitas dan karakteristik tertentu yang ditetapkan oleh penelitian untuk dipelajari dan kemudian ditarik kesimpulannya." . Populasi dalam penelitian ini adalah 100 warga Kota Semarang. Analisis data dilakukan secara kuantitatif dengan menggunakan program statistik, yaitu SPSS (Statistical Product and Service Solutions) versi 25.0. Tujuannya adalah untuk mengetahui dan menetapkan apakah hipotesis akan diterima 
atau ditolak pada tingkat kesalahan yang ditetapkan. Metode analisis data yang digunakan dalam penelitian ini adalah sebagai berikut :

\section{Uji Kelayakan Data \\ Uji Validitas}

Validitas berasal dari kata validity yang mempunyai arti sejauh mana ketepatan dan kecermatan suatu alat ukur dalam melakukam fungsi ukurannya (Azwar 1986). Selain itu validitas adalah suatu ukuran yang menunjukkan bahwa variabel yang diukur memang benar-benar variabel yang hendak diteliti oleh peneliti (Cooper dan Schindler, dalam Zulganef, 2006). Cara yang paling sering digunakan untuk mengetahui validitas alat ukur adalah skor item dan skor totalnya. Koefesien korelasi antara skor dan skor totalnya harus signifikan.

\section{Uji Reliabilitas}

Reliabilitas berasal dari kata reliability. Pengertian dari reliability (rliabilitas) adalah keajegan pengukuran (Walizer, 1987). Sugiharto dan Situnjak (2006) menyatakan bahwa reliabilitas menunjuk pada suatu pengertian bahwa instrumen yang digunakan dalam penelitian untuk memperoleh informasi yang digunakan dapat dipercaya sebagai alat pengumpulan data dan mampu mengungkap informasi yang sebenarnya dilapangan. Ghozali (2009) menyatakan bahwa reliabilitas adalah alat untuk mengukur suatu kuesioner yang merupakan indikator dari peubah atau konstruk. Suatu kuesioner dikatakan reliabel atau handal jika jawaban seseorang terhadap pernyataan adalah konsisten atau stabil dari waktu ke waktu. Reliabilitas suatu test merujuk pada derajat stabilitas, konsistensi, daya prediksi, dan akurasi. Pengukuran yang memiliki reliabilitas yang tinggi adalah pengukuran yang dapat menghasilkan data yang reliabel

Menurut Masri Singarimbun, reliabilitas adalah indeks yang menunjukkan sejauh mana suatu alat ukur dapat dipercaya atau dapat diandalkan. Bila suatu alat pengukur dipakai dua kali - untuk mengukur gejala yang sama dan hasil pengukuran yang diperoleh relative konsisten, maka alat pengukur tersebut reliable. Dengan kata lain, realibitas menunjukkan konsistensi suatu alat pengukur di dalam pengukur gejala yang sama.

\section{Statistik Deskriptif}

Statistik Deskriptif yang digunakan untuk mengambarkan tentang deskripsi data dan ringkasan data penelitian seperti nilai minimum, nilai maximum, nilai mean dan standar deviasi.

\section{Uji Asumsi Klasik}

Uji Normalitas yaitu, dengan dasar pengambilan keputusan jika nilai signifikansi (Asymp. Sig) > 0,05 maka data residual dapat dikatakan terdistribusi dengan normal dan jika nilai signifikansi (Asymp. Sig) $<0,05$ maka data residual tidak terdistribusi dengan normal. 
Uji Multikolinearitas dengan dasar pengambilan keputusan dimana jika nilai Tolerance lebih dari 0,10 dan VIF kurang dari 10 maka tidak terjadi multikolinearitas.

Uji Heteroskedastisitas dengan dasar pengambilan keputusan jika nilai signifikansi $>0,05$ maka tidak terjadi heteroskedastisitas. Jika nilai signifikansi $<0,05$ maka kesimpulannya yaitu terdapat heteroskedastisitas.

Uji Autokorelasi dengan dasar pengambilan keputusan jika DW lebih kecil dari dL atau DW lebih besar dari (4-dL) yang berarti terdapat autokorelasi dan jika DW terletak antara dU dan (4-dU) yang berarti tidak ada autokorelasi sedangkan jika DW terletak antara dL dan dU atau diantara (4-dU) dan (4-dL), maka tidak menghasilkan kesimpulan yang pasti.

\section{Uji Hipotesis}

Penelitian ini menguji hipotesis dengan analisis regresi berganda. Tujuan dari penelitian ini adalah untuk menguji apakah persepsi resiko bepengaruh terhadap niat beli online dengan keputusan pembelian sebagai variabel mediasi. Persamaan struktual dalam penelitian ini adalah :

$$
Y_{1}=\beta_{1} X_{1}+e
$$

Keterangan :

Y1 = Keputusan Pembeliaan

$\beta_{1=}$ Koefisien jalur dari Persepsi Resiko

$X_{1}=$ Persepsi Resiko

$\mathrm{e}=\operatorname{eror}(10 \%)$

$$
Y_{2}=\beta_{1} X_{1}+e
$$

Keterangan :

$\mathrm{Y}_{2}=$ Niat Beli Online

$B_{1}=$ Koefisien jalur dari Keputusan Pembeliaan

$X_{1}=$ Persepsi resiko

$Y_{1}=$ Keputusan Pembelian

$\mathrm{e}=\operatorname{eror}(5 \%)$

\section{Path Analysis ( Uji Jalur Path)}

Analisis jalur adalah bagian dari model regresi yang dapat digunakan untuk menganalisis hubungan sebab akibat antar satu variabel dengan variabel lainnya. Analisis jalur digunakan dengan menggunakan korelasi, regresi dan jalur sehingga dapat diketahui untuk sampai pada variabel dependen terakhir, harus lewat jalur langsung atau melalui variabel intervening (Sugiyono, 2013).

\section{Uji Koefisien Determinasi}

Analisis ini akan digunakan dengan menguji besarnya kontribusi yang ditunjukan oleh koefisien jalur pada setiap diagram jalur dari hubungan kausal antara 
variabel $\mathrm{X}$ terhadap $\mathrm{Y}$ kemudian $\mathrm{X}$ dan $\mathrm{Y}$ terhadap $\mathrm{Z}$, yang dinyatakan dalam persentase. Analisis ini dapat menggunakan rumus :

$$
\mathrm{KD}=\mathrm{rxy}^{2} \times 100 \%
$$

Dimana :

$\mathrm{KD}=$ Seberapa besar perubahan variabel independen terhadap variabel dependen

$\mathrm{r}_{x y^{2}}=$ Kuadrat koefisien jalur pada setiap diagram jalur

Kriteria untuk analisis koefisien determinasi adalah :

a. Jika KD mendekati nol, berarti pengaruh variabel independen terhadap variabel dependen rendah.

b. Jika KD mendekati satu, berarti pengaruh variabel independen terhadap variabel dependen kuat.

\section{HASIL PENELITIAN}

Berdasarkan hasil analisis yang dilakukan maka, dapat disimpulkan sebagai berikut :

Pengaruh Persepsi Resiko (X1) Terhadap Keputusan Pembeliaan (Y2)

Pada hasil output SPSS menunjukan variabel Persepsi Resiko (X1) t hitung sebesar 1,910 dengan nilai signifikansi sebesar 0,059. Karena nilai $t$ hitung $1,910<\mathrm{t}$ tabel 1,984 dan nilai signifikansi (Sig.) 0,059>0,05. Berdasarkan hasil tersebut Persepsi Resiko (X1) secara parsial tidak mempengaruhi Keputusan Pembeliaan (Y2).

\section{Pengaruh Persepsi Resiko (X1) Terhadap Niat Beli Online (Y1) Dengan Keputusan Pembelian (Y2) Sebagai Variabel Intervening}

Pada hasil Sobel Test menunjukan pengaruh variabel Niat Beli Online (Y1) sebagai variabel mediasi berpengaruh tidak langsung dari variabel Persepsi Resiko (X1) terhadap Keputusan Pembeliaan (Y2) mendapatkan hasil signifikansi 0,00001199. Karena hasil Sobel Test 0,00001199 < 0,05 (sig). Maka dapat disimpulkan bahwa Persepsi Resiko (X1) melalui Keputusan Pembelian (Y2) berpengaruh terhadap Niat Beli Online (Y2). Dari hasil tersebut diketahui Keputusan Pembelian (Y2) mampu memediasi pengaruh Persepsi Resiko (X1) terhadap Niat Beli Online (Y1).

\section{Pengaruh Niat Beli Online (Y1) Terhadap Keputusan Pembeliaan (Y2)}

Pada hasil output SPSS menunjukan variabel Niat Beli Online (Y2) $t_{\text {hitung }}$ sebesar 8,925 dengan tingkat signifikansi sebesar 0,000. Karena nilai $t_{\text {hitung }} 8,925>t$ tabel 1,984 dan nilai signifikansi (Sig.) $0,000<0,05$. Berdasarkan hasil tersebut Niat Beli Online (Y2) secara parsial berpengaruh terhadap Keputusan Pembeliaan (Y2).

\section{KESIMPULAN}

a. Berdasarkan hasil analisis Persepsi Resiko secara parsial tidak berpengaruh terhadap Keputusan Pembeliaan. Pada hasil output SPSS menunjukan variabel Persepsi Resiko $(X 1) \mathrm{t}$ hitung sebesar 1,910 dengan nilai signifikansi sebesar 0,059. Karena nilai $\mathrm{t}$ hitung 1,910 < t tabel 1,984 dan nilai signifikansi (Sig.) 0,059>0,05. Berdasarkan hasil tersebut Keputusan Pembelian (Y2) secara parsial tidak mempengaruhi. Pengaruh 
Persepsi Resiko yang dimediasi Keputusan Pembelian secara parsial mempengaruhi Niat Beli Online. Pada hasil Sobel Test menunjukan pengaruh variabel Keputusan Pembelian (Y1) sebagai variabel mediasi pengaruh tidak langsung dari variabel Persepsi Resiko (X1) terhadap Nit beli Online (Y2) mendapatkan hasil signifikansi 0,00001199. Karena hasil Sobel Test 0,00001199 < 0,05 (sig). Keputusan Pembelian secara parsial berpengaruh terhadap niat beli online. Diharapkan, Peneliti selanjutnya dapat mengganti atau menambahkan variabel independen, atau variabel intervening dengan variabel lain yang sesuai dengan keperluan penelitian.Peneliti selanjutnya dapat memperluas sampel khususnya Konsumen Toko Online, serta dapat memperpanjang periode penelitian sehingga mendapatkan data sampel yang banyak dan lebih akurat.

\section{DAFTAR PUSTAKA}

Suresh, A. M., \& Shashikala, R. (2011). Identifying factors of consumer perceived risk towards online shopping in India. In 3rd International Conference on Information and Financial Engineering IPEDR (Vol. 12, No. 336-341).

Baskara, I. P., \& Hariyadi, G. T. (2014). Analisis pengaruh kepercayaan, keamanan, kualitas pelayanan dan persepsi akan resiko terhadap keputusan pembelian melalui situs jejaring sosial. Studi pada Mahasiswa di Kota Semarang, Universitas Dian Nuswantoro, Semarang, 1-15. Arikunto, Suharsimi. 2002. Metode Penelitian. Jakarta: Rineka Cipta

Kotler, P., \& Armstrong, G. (2008). Prinsip-prinsip pemasaran..

Casaló, L. V., Flavián, C., \& Guinalíu, M. (2010). Generating trust and satisfaction in eservices: the impact of usability on consumer behavior. Journal of Relationship Marketing, 9(4), 247-263.

Cetak Penjualan Rp 54 T, Shopee E-Commerce Terpopuler di Asia Tenggara (https://katadata.co.id/berita/2019/08/23/cetak-penjualan-rp-54-t-shopee-ecommerce-terpopuler-di-asia-tenggara) Delgado-Ballester, E., Munuera-Aleman, J.L. (2001). Brand trust in the context of consumer loyalty. European Journal of Marketing, 35 (11/12), 1238-1258. pp.

Suryaningrum, F. P., Haryono, A. T., \& Amboningtyas, D. (2019). PENGARUH LINGKUNGAN KERJA NON FISIK, KOMPENSASI, KEPUASAN KERJA, TERHADAP KINERJA KAYAWAN, DAN KOMITMEN ORGANISASI SEBAGAI VARIABEL MEDIASI (Studi Kasus di PT. Bagus Conveksi Branch Paragon Mall Semarang). JURNAL EKBIS: ANALISIS, PREDIKSI DAN INFORMASI, 20(2), 1320-1331.

Alma, B. (2004). Manajemen Pemasaran dan Pemasaran Jasa, cetakan kelima. Penerbit: Alfabeta, Bandung. 
Park, C.H., \& Kim,Y.G. (2003). Identify key factors affecting consumer purchase behaviour in an online shopping context. International Journal of Retail \& Distribution Management.

Parasuraman, A., Berry, Leonard L, and Zeithaml, Valarie A. 1994. "Reassessment of Expectations as a Comparison Standar in Measurung Service Quality: Implications for Future Research,. Journal of Marketing, Vol;. 58 (January), pp. 111-124.

Raman, Arasu., \& Viswanathan, A. (2011). "Web Services and e-Shopping Decisions: A Study on Malaysian e-Consumer". IJCA Special Issue on:Wireless Information Networks \& Business Information System, hal.54-60.

Syairozi, M. I., \& Fattah, A. (2018). "Youth Creative Enterpreneur Empowerment (YOUTIVEE)": Solusi Bagi Kaum Muda untuk Berkonstribusi pada Perekonomian dan Mengurangi Pengangguran. Jesya (Jurnal Ekonomi \& Ekonomi Syariah), 1(2), 43-55.

Syairozi, M. (2015). Pengaruh Faktor Eksternal (Inflasi, Bunga) Dan Faktor Internal (Bagi Hasil, Jumlah Bank) Terhadap Deposito Mudharabah Pada Perbankan Syariah Di Indonesia (Doctoral dissertation, Universitas Brawijaya).

Sangadji, E. M., \& Sopiah, 2013. Consumer Behavior: Perilaku Konsumen dan Strategi Pemasaran Jilid 2. Jakarta: Erlangga.

Sinambela, Lijan Poltak. 2008. Reformasi Pelayanan Publik Teori, Kebijakan, dan Implementasi. Jakarta : PT Bumi Aksara

Singarimbun, Masri dan Effendi, Sofyan. 1996. Metode Penelitian Survey, Edisi Revisi, Cetakan Pertama. Jakarta: LP3ES

Sugiyono,2014. Metode Penelitian Kuantitatif, Kualitiatif dan R\&D. Bandung: Alfabeta.Sukawati .2018. Pengaruh Kepercayaan, Harga, dan kualitas produk terhadap keputusan pembelian melalui internet di kota Makasar. Jurnal Universitas Negeri Makasar.

S. Sinambela.2010.Pengaruh Merk dan Dimensi Kualitas Pada produk sepatu olahragaNike terhadap Keputusan Pembelian. Jurnal Universitas Mpu Tantular Jakart.

Shalhoub Karake, 2006, Trust, Privacy, and Security in Electronic Business: the case of GCC countries, Emerald: International Management \& Computer Security Journal, no. 0968- 5227. US

Sugiyono. 2012. Metode Penelitian Pendidikan Kuantitatif, Kualitatif dan R\&D. Bandung: CV. Alfabeta.

Swastha, B. dan Irawan. 2000. Manajemen Pemasaran Modern. Liberty. Yogyakarta.

Tjiptono, Fandy. 2008. Strategi Pemasaran. Edisi 3. ANDI: Yogyakarta.

Tjiptono, F., dan Chandra,G.2009.Pemasaran Strategik.ANDI offset. Yogyakarta. 
Tjiptono, Fandy. 2011. Pemasaran Jasa. Penerbit Banyumedia Publishing. Malang

Widiyanto, Joko. 2010. SPSS For Windows Analisis Data Statistik Dan Penelitian. Surakarta

Zulfikar, 2016. Pengantar Pasar Modal dengan Pendekatan Statistika, Yogyakarta : Depublish 